\title{
Old songs can be as fresh as new: An ERP study on lyrics processing
}

\author{
Pei-Ju Chien, Shiao-hui Chan* \\ Department of English, National Taiwan Normal University, Taipei, Taiwan
}

\section{A R T I C L E I N F O}

\section{Article history:}

Received 5 November 2014

Received in revised form 3 February 2015

Accepted 18 February 2015

Available online 11 March 2015

\section{Keywords:}

Song lyrics

Familiarity

Semantic processing

N400

Mandarin

\begin{abstract}
A B S T R A C T
Song familiarity has been systematically found to have a strong effect on music cognition, especially in aspects of emotion and memory; however, whether it would also influence the semantic processing of song lyrics is unclear. To address this, we asked subjects to listen to familiar and unfamiliar pop song excerpts, which were followed by visual target words semantically related or unrelated to the lyrics-final word, and to judge the concreteness of the targets. The ERP results revealed that larger N400 was elicited by unrelated visual targets compared with related ones, indicating that the subjects processed the meaning of the preceding lyrics even though that was not part of the required task. More importantly, the N400 relatedness effect did not vary with subjects' familiarity with the songs, suggesting that the subjects kept processing the meaning of the lyrics even though they had listened to the songs multiple times. The fact that repetition-the essential characteristic of familiar songs-did not diminish the meaning processing of lyrics suggests that lyrics and speech may differ at a higher communicative level.
\end{abstract}

() 2015 Elsevier Ltd. All rights reserved.

\section{Introduction}

Many of us listen to songs every day. Do we pay attention to what the lyrics are saying? Or, more interestingly, do we still process the meaning of the lyrics even when a song has been listened to many times?

\footnotetext{
* Corresponding author. No.162, Sec. 1, Heping E. Rd., Da'an Dist., Taipei City 106, Taiwan, ROC. Tel.: +886 277341544. E-mail addresses: jpl_helen@hotmail.com (P.-J. Chien), shiaohui@gmail.com (S.-h. Chan).
} 
One of the major issues in song perception literature is to address how, instead of whether, lyrics are processed. Specifically, the focus has been on whether lyrics and melody are processed independently or interactively when people listen to a song. Findings in neuropsychological studies support the independent view. Patients with temporal lobe damage demonstrated dissociation between lyrics and tunes in song memory (Hébert \& Peretz, 2001, 1996; Samson \& Zatorre, 1991) and nonfluent aphasics had better production in melody than lyrics (i.e. producing more notes than words) (Hébert, Racette, Gagnon, \& Peretz, 2003; Racette, Bard, \& Peretz, 2006). Studies with normal subjects also bolster the independent view. Divided attention studies showed that subjects performed equally well in detecting either the semantic or melodic incongruity (single task) or both (dual task) (Bonnel, Faita, Peretz, \& Besson, 2001). An event-related potential (ERP) study also revealed that semantic anomalies elicited a widespread N400, harmonic anomalies induced a parietal P300, and the mean amplitudes of the double-incongruity condition were not statistically different from the predictions of an additive model of semantic and harmonic processing (Besson, Faïta, Peretz, Bonnel, \& Requin, 1998).

In contrast, evidences supporting the integration of lyrics and tune in song processing have also been reported. Studies on song memory have shown that melodies and lyrics are better recognized when heard in their original form (i.e. melodies with original text and lyrics with original melody) than in a modified version (Crowder, Serafine, \& Repp, 1990; Morrongiello \& Roes, 1990; Samson \& Zatorre, 1991; Serafine, Crowder, \& Repp, 1984; Serafine, Davidson, Crowder, \& Repp, 1986). Also, researchers have unveiled that, musical context, like regular linguistic context, can modulate phonemic and semantic processing in songs. Phoneme monitoring was faster when the target phonemes were sung on a referential tonic chord than on a less referential subdominant chord (Bigand, Tillmann, Poulin, D'Adamo, \& Madurell, 2001), and semantic priming was modulated by harmonic structure, replicating the effect of semantic context on lexical decision tasks widely documented in psycholinguistics (Poulin-Charronnat, Bigand, Madurell, \& Peereman, 2005). In fact, researchers supporting the interactive view of song perception have claimed that music and lyrics share underlying mechanisms. When non-musicians (subjects without musical training) were asked to judge whether the prime and target were the same while paying attention to either the linguistic or the musical aspect of songs, the N400s to sung words were modulated by melody, suggesting shared processing resources between the phonological/semantic aspects of language and the melodic/harmonic aspects of music (Gordon, Schön, Magne, Astésano, \& Besson, 2010). In musically educated adults, harmonic violations in music elicited positivities similar in latency but different in topography (antero-temporal righthemisphere lateralization) from the P600 found in syntactic violations in language (Patel, Gibson, Ratner, Besson, \& Holcomb, 1998). Also, in non-musicians, an early right-anterior negativity (ERAN) was found to be sensitive to the degree of musical expectancy induced by the preceding musical context, similar to the early left-anterior negativity (ELAN) associated with local structure violation in linguistic processing (Koelsch, Gunter, Friederici, \& Schröger, 2000). Imaging studies have further clarified the underlying neurological structures of previous ERP findings. A magnetoencephalography (MEG) study showed that, similar to ELAN, ERAN originates in Broca's area and its right hemisphere homolog in non-musicians (Maess, Koelsch, Gunter, \& Friederici, 2001). fMRI studies demonstrated that the cortical brain regions known to support language processing also serve the processing of musical sequences or songs (Koelsch, Gunter, Zysset, Lohmann, \& Friederici, 2002; Merrill et al., 2012).

A recent fMRI study seems to hint that there may be a middle ground between the independent and interactive views (Sammler et al., 2010). With the use of an adaptation paradigm, various regions along the bilateral superior temporal sulcus and gyrus (STS/STG) were found to be associated with independent or interactive processing of lyrics and melody: the left mid-STS (inferior to Heschl's gyrus) being associated with an interaction of lyrics and tunes at prelexical, phonemic processing levels, the left anterior STS with an independent processing of lyrics at semantic levels, and the left dorsal precentral gyrus with an integrated representation of lyrics and tunes for fusing musical and linguistic features (no region showed a predominance for tunes, possibly due to the nature of the experimental task). This study revealed that the independent/interactive views about lyrics and melody processing might represent the extremes of a continuum with different degree of interaction/independence at different stages of song perception (Sammler et al., 2010).

To sum up, whether melody and language are processed independently or interactively is still under debate; nevertheless, researchers seem to generally agree/assume that lyrics are processed in the same 
manner as regular linguistic materials in many respects, including meaning processing. ERP studies, in particular, showed that semantic incongruity in lyrics triggered an N400 effect, just like what would be expected when a semantic anomaly was encountered in a sentence (Besson et al., 1998; Gordon et al., 2010; Kutas \& Federmeier, 2011; Kutas \& Hillyard, 1980, 1984).

Interestingly, although all the above researchers clearly had the factor of song familiarity in mind by specifying whether their song material was familiar or not in their reports, the effect of familiarity was somehow overlooked and was rarely manipulated in the studies (but see Sammler et al., 2010). What effect would song familiarity bring to listeners in song perception? An MEG study found that familiar songs exerted a top down effect on song perception such that the brain response to melodic deviants appeared as early as $130 \mathrm{~ms}$ in the right hemisphere and that to linguistic deviants occurred as early as $140 \mathrm{~ms}$ in the left hemisphere (Yasui, Kaga, \& Sakai, 2009). As impressively rapid as it may be, fast recognition may simply be a by-product effect that familiar songs bring to listeners in everyday life. The major effect of familiar songs may lie in its ability to induce listeners' emotion and/ or memory.

Researchers have systematically studied the familiarity effect on emotion and memory in the realm of music cognition. Offline ratings have clearly shown that familiarity with songs increased the subjective rating of the meaningfulness of lyrics (i.e. whether they are informative, persuasive, generate strong and multiple associations, etc.), even when the familiarity was achieved by merely exposing subjects to an unfamiliar song (Thompson \& Russo, 2004). Neuroimaging studies have also revealed the connection between familiar music and emotion. Emotion-related limbic and paralimbic regions as well as the reward circuitry were significantly more active for familiar relative to unfamiliar music, showing that familiarity could be a crucial factor in making listeners emotionally engaged with music (Pereira et al., 2011). Also, when subjects heard popular music excerpts dating to their extended childhood, dorsal regions of the medial prefrontal cortex (MPFC) responded parametrically to the degree of autobiographical salience experienced over the course of the individual excerpts, suggesting that the dorsal MPFC associates music and memories when people experience emotionally salient episodic memories (Janata, 2009).

Although it is apparent that familiar songs induce different brain response than unfamiliar songs do, especially in those brain regions related to emotion and memory, it remains to be seen whether song familiarity would influence the online semantic processing of lyrics. Familiarity of music is mainly achieved through repetition (Peretz, Gaudreau, \& Bonnel, 1998; Thompson \& Russo, 2004); however, while the verbatim content in music retains communicative significance across repetitions, repetition of a word causes it to shed its semantic associations and fall into nonsense-a phenomenon called "semantic satiation" (Margulis, 2013; Severance \& Washburn, 1907). It is thus important to find out whether repetition would diminish the semantic processing of lyrics in familiar songs, just like what it normally does to regular linguistic materials.

To address whether lyrics are processed semantically, the experimental design and task would also have a direct impact on the outcome. Although all the studies reviewed above suggested that lyrics are similarly processed as regular linguistic materials, most of the results were obtained from experiments with songs altered from their original form or with experimental tasks designed to intentionally direct subjects' attention to the lyrics (or melody). For example, songs in some of the studies were sung or synthesized a cappella (i.e. without musical instruments accompanied) (Besson et al., 1998; Bonnel et al., 2001; Sammler et al., 2010; Yasui et al., 2009), which is not usually how vocal music is perceived in daily life. Also, many of the studies directed subjects' attention to the presented lexical item (e.g. word vs. nonwords in Poulin-Charronnat et al., 2005), the semantic/physical congruity of lyrics (semantic congruity: Besson et al., 1998; Bonnel et al., 2001; physical congruity: Gordon et al., 2010), or the familiarity with or memory of songs (Crowder et al., 1990; Hébert \& Peretz, 2001; Serafine et al., 1984), which might have had subjects intentionally attend to the meaning of lyrics and thus induced the observed linguistic processing. Since such use of materials or tasks is more or less deviant from listeners' everyday experience of song perception, it is important to test the ecological validity of current understanding of lyrics perception to see whether people still automatically comprehend song lyrics when they are not intentionally directed toward the meaning of the lyrics and when the songs are kept in their original form (i.e. not altered for a laboratory setting). 
In sum, the main purpose of the present study was to examine whether people process the meaning of song lyrics spontaneously and whether song familiarity would reduce the degree of meaning processing.

\section{Material and methods}

\subsection{Subjects}

Twenty-three Mandarin native speakers (mean age 23, 14 females) were recruited for the experiment. All the subjects had no formal musical training background and had a habit of listening to Mandarin pop music by self-report. They were all right-handers according to a simplified version of the Edinburg handedness inventory (Oldfield, 1971). None of the subjects had known hearing, reading or neurological problems nor did they use any medication before the experiment. Informed consent following the Linguistic Society of Taiwan Research Ethics Guidelines was obtained prior to the experiment. All subjects were paid when finishing the experiment.

\subsection{Materials}

We chose pop songs as experimental materials because they were usually listened to by people in all sorts of natural settings-at work, at home, during commuting, etc. Mandarin pop song lyrics were used and were divided into two conditions, familiar and unfamiliar. Familiar songs were collected based on the yearly billboards of an online music database in Taiwan (KKBOX, http://www.kkbox.com/ tw/tc/index.html). The billboards could represent familiarity of songs to the general public for its ranking was based on how many times the songs were listened to by online members. Unfamiliar songs were chosen from non-mainstream Mandarin albums (including, but not limited to, independent music) released in Taiwan that were much less known by most audience. The familiar and unfamiliar songs were both produced with musical instruments but were different in the following aspects. First, the themes of familiar songs were mainly about love, while those of unfamiliar songs were more diverse. Also, there was extensive sound editing or audio mixing in familiar songs, but there was not as much editing/mixing in unfamiliar ones. Finally, and most relevant to the current study, the chorus is usually long and repeated many times in a familiar song, while that in an unfamiliar song is usually short and not repeated as much. Based on the last characteristic distinguishing between familiar and unfamiliar songs, the first or first two sentences in the chorus, which conveyed complete sense and ended with a noun, were extracted from the familiar lyrics as song primes since the sentence(s) was usually regarded as the most familiar part to people in a song. The same manner of extracting lyrics materials was applied to the unfamiliar song condition. The chosen sentence(s) was limited to within 25 syllables to control for the length of all the lyrics stimuli. See Table 1 for the example materials in the familiar and unfamiliar conditions.

The following factors were carefully controlled for the song primes: familiarity (familiar vs. unfamiliar), cloze probability in the unfamiliar lyrics (averaged cloze probability: 31\%), syllable number (i.e. length of the presented lyrics) and syllable to lyrics length ratio (i.e. to control for the speed of the

Table 1

Example materials in the experiment.

\begin{tabular}{|c|c|c|c|c|}
\hline \multirow[t]{2}{*}{ Condition } & \multirow[t]{2}{*}{ Auditory song prime } & \multirow{2}{*}{$\begin{array}{l}\text { Final noun of } \\
\text { song prime }\end{array}$} & \multicolumn{2}{|c|}{ Visual target } \\
\hline & & & Related & Unrelated \\
\hline Familiar & $\begin{array}{l}\text { wo bi xu shuo wo zhen de bu hui xi huan ni/wo bu xi huan ni zhan } \\
\text { ju wo suo you si xu } \\
\text { I have to say that I won't like you./I don't like that you are all my } \\
\text { thoughts }\end{array}$ & $\begin{array}{l}\text { si } \mathrm{xu} \\
\text { thoughts }\end{array}$ & $\begin{array}{l}\text { tou nao } \\
\text { brain }\end{array}$ & $\begin{array}{l}\text { chan liang } \\
\text { production }\end{array}$ \\
\hline Unfamiliar & $\begin{array}{l}\text { qi shi wo hai shi hui zai hu mei yi pian shu ye dao da zhuo } \\
\text { shang de shi jian } \\
\text { In fact I still care about the time for every piece of leaf to get to the table. }\end{array}$ & $\begin{array}{l}\text { shi jian } \\
\text { time }\end{array}$ & $\begin{array}{l}\text { shi zhong } \\
\text { clock }\end{array}$ & $\begin{array}{l}\text { lu ren } \\
\text { passers-by }\end{array}$ \\
\hline
\end{tabular}


song). For song familiarity, 30 Mandarin-speaking subjects with the habit of listening to Mandarin pop music, who did not participate in the ERP experiment, were asked to evaluate the familiarity of selected song excerpts on a 5-point scale (5: most familiar, 1: least familiar). A significant difference was found between the familiar and unfamiliar songs $(t(126)=13.62, \mathrm{p}<.001)$. The factor of cloze probability was also considered. Since the cloze probability of the sentence-final words in familiar songs should be high (or even close to $100 \%$ since people would use the expected words to finish the lyrics for they were familiar with the songs), only the cloze probability of the sentence-final words in unfamiliar songs was measured to see if there was a possibility to match the high cloze probability in familiar songs. A pilot test with 4 questionnaires was conducted. The unfamiliar lyrics with their sentence-final position left blank were included in the questionnaires. Twenty Mandarin native speakers, who did not participate in the ERP study, were recruited for each of the questionnaires to fill in the sentence-final position of the unfamiliar lyrics. The results showed a wide range of cloze probability distribution: only $3 \%$ of the lyrics completions had a cloze probability above $70 \%$ and almost half of the completions of the lyrics had zero cloze probability. As it became difficult to make the same control on the cloze probability between familiar and unfamiliar song conditions, only those unfamiliar lyrics whose completions had a cloze probability of $5 \%$ or more (i.e. at least one subject filled in the blank with the expected word) were selected. The final cloze probability for the unfamiliar lyrics was $31 \%$. To control the speed of the songs, the number of fast and slow songs used in both song conditions was balanced based on the ratio of the number of syllables to the length of the song excerpt. In the end, a total of 120 song excerpts were selected: 60 familiar and 60 unfamiliar songs, with each familiarity category containing 35 slow (about 1 syllable per second) and 25 fast (about 2 syllables per second) songs. No sentence-final words were repeated in the selected lyrics materials. No significant difference was found in syllable number $(\mathrm{t}(59)=1.83, \mathrm{p}=.072)$ and in syllable to lyrics length ratio across the familiar and unfamiliar song conditions $(\mathrm{t}(59)=-1.51, \mathrm{p}=.135)$.

Since a semantic priming paradigm was used in the ERP experiment-with the final noun of the lyrics as the prime word and a visually presented word as the target that was either semantically related or unrelated to the final noun-another pilot test was conducted to construct the materials after the song excerpts were finalized. For the semantically-related targets, subjects were recruited to write down the first two words they could think of that were most related to the prime words provided. The 120 prime words (from both familiar and unfamiliar lyrics) were divided into two questionnaires and 20 Mandarin native speakers were recruited for each questionnaire. With the answers given by the subjects, 120 words related to the primes were decided. Another 120 words not given by the subjects as responses were constructed as unrelated targets. To ensure difference in relatedness between the two types of target words, another pilot test on word pair relatedness rating was conducted (e.g. si xu (thoughts) vs. tou nao (brain); si xu (thoughts) vs. chan liang (production)). The 240 prime-target word pairs were randomized and divided into two questionnaires to avoid the same prime appearing in one questionnaire twice. Twenty Mandarin native speakers were recruited for each questionnaire and were asked to rate the relatedness of the pairs on a 5-point scale (5: strongly related, 1: weakly related). A two-way analysis of variance (ANOVA) with the factors of relatedness and familiarity showed that there was a main effect of relatedness between the related and unrelated prime-target pairs $(F(1,59)=2323.05, p<.001)$. There was no main effect of familiarity $(F(1,59)=2.39, p=.127)$ and no two-way interaction of familiarity and relatedness $(F(1,59)=.62, \mathrm{p}=.432)$. Finally, the word frequency of the 120 semantically-related and 120 semantically-unrelated target words was examined by referencing to the Corpus of Chinese Word Frequency constructed by Institute of Linguistics, Academia Sinica (http://elearning.ling.sinica.edu.tw/CWordfreq.html). Statistical analysis showed no significant difference in word frequency with regard to the factors of familiarity and relatedness (familiarity: $\mathrm{F}(1,59)=.20, \mathrm{p}=.657$; relatedness: $\mathrm{F}(1,59)=.006, \mathrm{p}=.937$; familiarity $\times$ relatedness: $\mathrm{F}(1,59)=1.50$, $\mathrm{p}=.225)$.

In sum, with the pilot tests, the materials were ensured not to be biased by potential confounds. See Table 2 for the summary of the statistical results for all the pilot tests.

Since subjects' task in the experiment was to judge the concreteness of the targets (described in more detail in Procedure below), a final pilot test was conducted to determine the concreteness of the targets so that the results could be used to determine the accuracy of subjects' responses later in the ERP experiment. Twenty-one Mandarin speakers were recruited to judge whether the targets were 
Table 2

Summary of the statistical results for the materials.

\begin{tabular}{llll}
\hline Material & Factor & Comparison & $\mathrm{p}$-value \\
\hline Song lyrics & Song familiarity & Familiar vs. Unfamiliar & $.000^{*}$ \\
& Syllable number of the lyrics & Familiar vs. Unfamiliar & .072 \\
& Syllable to lyrics length ratio & Familiar vs. Unfamiliar & .135 \\
Target & Relatedness & Related vs. Unrelated & $.000^{*}$ \\
& & Familial vs. Unfamiliar & .127 \\
& Word frequency & Familiarity $\times$ Relatedness & .432 \\
& & Related vs. Unrelated & .937 \\
& & Familiar vs. Unfamiliar & .657 \\
& Familiarity $\times$ Relatedness & .225 \\
\hline
\end{tabular}

concrete or abstract, and the result showed that there were 76 concrete targets in the related condition while there were 88 concrete nouns in the unrelated condition (those nouns indicated by at least 11 subjects as concrete were considered concrete nouns).

Four versions of experimental trials were constructed so that the 120 excerpts of lyrics stimuli were counterbalanced across the semantically related and unrelated target conditions. As a result, each subject only heard each excerpt once, with the prime word pairing with either the semantically related or the unrelated target.

\subsection{Procedure}

The experiment was conducted in a sound-attenuated chamber. The subjects were instructed to sit in front of a computer screen, and the distance between the subjects' eyes and the computer screen was about $90 \mathrm{~cm}$. Each trial started with a 500-ms fixation point "+" on the center of the screen. Then the subjects were presented aurally with a short excerpt of lyrics displayed by a speaker while looking at an asterisk sign "**" on the screen to reduce eye movements, and $450 \mathrm{~ms}$ after the end of the auditory stimulus presentation, a target word appeared on the screen. The subjects were asked to decide whether the presented word was a concrete or an abstract noun by pushing one of the buttons on a response box. Their response hands were counterbalanced so that half of the subjects used their right hand and the other half used their left hand to respond. The subjects' response to the word concreteness task was self-paced, but an upper limit of $3 \mathrm{~s}$ was set so that the experiment could continue automatically. They were reminded not to blink on seeing the target words. After the response was made, there was a 2 -sec blank and then the central fixation point appeared to signal start of the next trial. The experimental procedure of stimuli presentation is illustrated in Fig. 1. All the auditory stimuli, each lasting from 5 to $18 \mathrm{~s}$, were made with Audacity 2.0 (http://audacity.sourceforge. net/) and the target words (font: PMingLiU, size: 24, color: black) were presented with the E-Prime 2.0 software (Psychology Software Tools, Inc.).

The subjects were given 9 practice trials to acquaint themselves with the experimental procedure. During the experiment, a sign indicating a short break popped up on the screen every 30 trials to avoid subjects' fatigue. The subjects could press any button on the response box to continue the experiment when they were ready. The length of the experiment was about $20 \mathrm{~min}$. After finishing the experiment, the subjects were given a questionnaire and were presented with all the song stimuli again. They had to indicate on the questionnaire whether they were familiar with the songs used in the experiment. The questionnaire survey took about $20 \mathrm{~min}$.

\subsection{Behavioral and EEG recording}

The electroencephalogram (EEG) was recorded (NuAmps, NeuroScan, Inc.) from 32 electrodes mounted on an elastic cap based on the international 10-20 system. Two reference points were placed on both sides of the mastoids. Two electrodes were placed at the corner of the left and right eyes, and two at the upper and the lower ridge of the left eye to monitor eye movements. Scalp ERPs were referenced to an average of the right and left mastoids for off-line analysis. The impedance of all the 


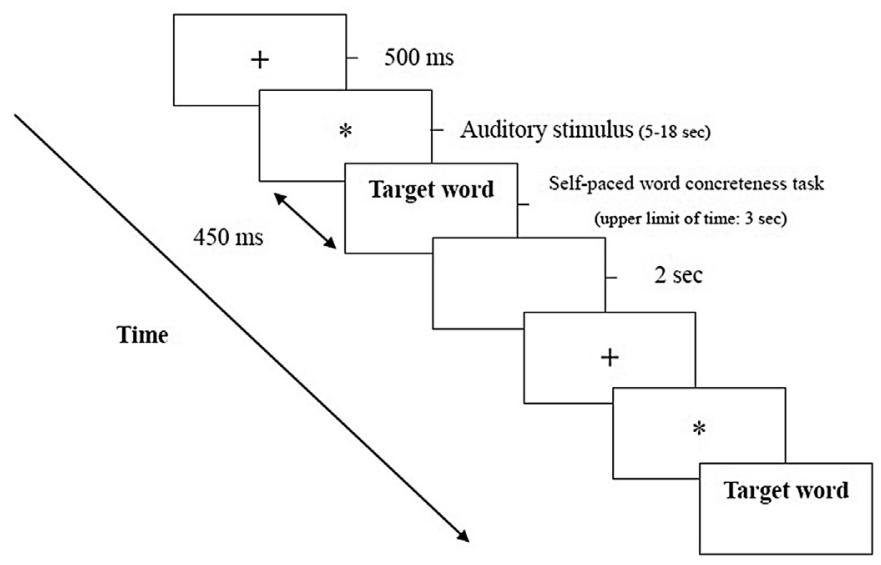

Fig. 1. Procedure of stimulus presentation. Each trial began with a central fixation point. The subjects were first presented with an auditory song stimulus for 5-18 s and, $450 \mathrm{~ms}$ after the end of the stimulus presentation, they were presented with a visual target word on the computer screen. On seeing the target word, they needed to perform a word concreteness task to judge if the target word was concrete or abstract. After the response to the concreteness task, a 2-sec blank appeared, followed by a central fixation point indicating the upcoming trial.

electrodes was kept at or below $5 \mathrm{k} \Omega$. The sampling rate (A/D rate) was $1000 \mathrm{~Hz}$ and the amplifier rate (Gain) was 19, corresponding to an input range of $\pm 131.5 \mathrm{mV}$. The EEG was filtered online between DC to $100 \mathrm{~Hz}$.

\subsection{Data analysis}

The raw EEG data from each subject were processed with the EDIT 4.5 software (NeuroScan Inc.). Linear derivation was first conducted to convert the four monopolar channels recording eye movement to two bipolar channels, VEOG and HEOG. Then, ocular movement reduction was applied by setting the trigger as positive and the threshold as $10 \%$. Twenty sweeps and 400 -ms duration were set as the blink value, and VEOG was chosen as the referred channel to monitor blinks. After the ocular movement was reduced, the continuous EEG data were epoched. For the song primes, the data were epoched from $200 \mathrm{~ms}$ before to $5000 \mathrm{~ms}$ after the onset of the auditory stimulus; for the visual targets, the data were epoched from $200 \mathrm{~ms}$ before to $1000 \mathrm{~ms}$ after the stimulus. The epoched files were baseline corrected with the pre-stimulus interval of -200 to $0 \mathrm{~ms}$. Artifact rejection was then carried out by reviewing the epochs and rejecting those contaminated by excessive eye movements, skin potentials, channels saturation or other body movements. The averaged rejection rate for the primes and the targets combined was $25 \%$, with $22 \%$ for the primes and $28 \%$ for the targets. The data from four of the subjects were excluded because their averaged rejection rate was higher than $33 \%$. The 19 subjects' data were included for further statistical analysis. Sorting and averaging were carried out on the song primes and the targets based on the experimental conditions. Grand averaging was conducted by averaging all the subjects' averaged ERP data within the same experimental condition. Finally, band pass filtering $(0.1 \mathrm{~Hz}-30 \mathrm{~Hz}, 12 \mathrm{~dB} /$ oct, zero phase shift mode) was applied.

For the statistical analysis, behavioral data (reaction times (RTs) and error rates) were analyzed with a three-way repeated ANOVA with the factors of concreteness (concrete, abstract), familiarity (familiar, unfamiliar) and relatedness (related, unrelated) to examine the effectiveness of the word concreteness task. For the ERP data, mean amplitudes in the latency range from 0 to $2000 \mathrm{~ms}$ of the song primes and from 350 to $500 \mathrm{~ms}$ of the targets were measured. To better capture the scalp distribution of the brain activity, the channels were divided into the midline and the lateral regions. The midline electrodes included FZ, CZ and PZ. The lateral regions were separated into four sites: the left frontal site (LF), including FP1, F3 and FC3; the right frontal site (RF), including FP2, F4 and FC4; the left parietal site (LP), including $\mathrm{CP} 3, \mathrm{P} 3$ and $\mathrm{O} 1$; the right parietal site (RP), including $\mathrm{CP} 4, \mathrm{P} 4$ and $\mathrm{O} 2$. The mean amplitudes in 
the lateral regions were measured by averaging all the electrodes chosen in that area. Two two-way repeated ANOVAs with the factors of familiarity (familiar, unfamiliar) and electrode (FZ, CZ, PZ) and the factors of familiarity (familiar, unfamiliar) and region (LF, RF, LP, RP) were conducted on the song primes for the midline and lateral analysis, respectively. Also, two three-way repeated ANOVAs were conducted on the targets with the factors of familiarity (familiar, unfamiliar), relatedness (related, unrelated), and electrode (FZ, CZ, PZ), and the factors of familiarity (familiar, unfamiliar), relatedness (related, unrelated), and region (LF, RF, LP, RP) for the midline and lateral analysis, respectively. Posthoc pair-wise comparisons were carried out and Bonferroni corrected only when an ANOVA revealed a significant effect involving the factor(s) of familiarity and/or relatedness. In addition, the pvalues for the ERP results were adjusted with the Greenhouse-Geisser correction (Greenhouse \& Geisser, 1959) when the Mauchly's test of Sphericity was violated.

\section{Results}

\subsection{Behavioral data}

The 19 subjects' mean reaction times (RTs) and error rates are illustrated in Table 3. The RT was measured from the onset of the visual target to the moment the subjects pushed the button. The error rate was determined by comparing the subjects' concreteness judgment with the results of a previous pilot test (see Materials). Therefore, the error rate reflected the "disagreement" between the subjects in the ERP experiment and those in the pilot test, which served as an indication of whether the subjects were paying attention during the ERP experiment.

The subjects' RT data were submitted to an omnibus $2 \times 2 \times 2$ repeated measures ANOVA with the factors of concreteness (concrete, abstract), relatedness (related, unrelated) and familiarity (familiar, unfamiliar). The results showed that there was a main effect of concreteness $(F(1,18)=25.88, p<.001)$, with the concrete words being processed faster than the abstract ones. A relatedness $\times$ concreteness interaction was also found $(\mathrm{F}(1,18)=8.37, \mathrm{p}<.05)$. Further examination on the interaction revealed that, while there was no RT difference between related vs. unrelated targets in abstract nouns, the RT for related targets was longer than that for unrelated ones in concrete nouns $(\mathrm{t}(18)=3.87, \mathrm{p}<.005)$. Finally, no other main effects or interactions were found (familiarity: $\mathrm{F}(1,18)=.12, \mathrm{p}=.723$; relatedness: $\mathrm{F}(1,18)=1.94, \mathrm{p}=.181$; relatedness $\times$ familiarity: $\mathrm{F}(1,18)=.18, \mathrm{p}=.673$; familiarity $\times$ concreteness: $\mathrm{F}(1,18)=.91, \mathrm{p}=.352$; familiarity $\times$ relatedness $\times$ concreteness: $\mathrm{F}(1,18)=1.30$, $\mathrm{p}=.268$ ).

As to the error rates for the subjects' responses, an omnibus $2 \times 2 \times 2$ repeated measures ANOVA with the factors of concreteness, relatedness and familiarity was conducted. The results showed that, similar to the RT analysis, there were a main effect of concreteness $(F(1,18)=24.22, \mathrm{p}<.001)$ and a twoway interaction of relatedness and concreteness $(\mathrm{F}(1,18)=31.28, \mathrm{p}<.001)$. Follow-up pair-wise comparisons showed that while the error rate for unrelated concrete targets was lower than that for the related ones $(t(18)=3.48, \mathrm{p}<.05)$, the error rate for the unrelated abstract nouns was higher than that for the related ones $(\mathrm{t}(18)=-3.55, \mathrm{p}<.05)$. No other main effects or interactions were found (familiarity: $\mathrm{F}(1,18)=1.18, \mathrm{p}=.291$; relatedness: $\mathrm{F}(1,18)=1.94, \mathrm{p}=.180$; familiarity $\times$ relatedness: $\mathrm{F}(1,18)=2.62, \quad \mathrm{p}=.123$; familiarity $\times$ concreteness: $\mathrm{F}(1,18)=1.50, \mathrm{p}=.236$; familiarity $\times$ relatedness $\times$ concreteness: $F(1,18)=2.07, p=.167)$.

\section{Table 3}

Reaction times (ms) and error rates (\%) for the experimental conditions.

\begin{tabular}{llccc}
\hline Condition & $\mathbf{F R}^{\mathrm{a}}$ & $\mathbf{F U}^{\mathrm{b}}$ & $\mathbf{U R}^{\mathrm{c}}$ & $\mathbf{U U}^{\mathrm{d}}$ \\
\hline RTs $(\mathrm{ms})$ & $1124.11(213.59)$ & $1069.16(180.49)$ & $1109.74(216.93)$ & $1072.37(192.21)$ \\
Error rates (\%) & $10(0.07)$ & $10(0.08)$ & $10(0.06)$ & $10(0.06)$ \\
\hline
\end{tabular}

S.D. is indicated in parenthesis.

${ }^{\text {a }} \mathrm{FR}=$ familiar song with related target.

b $\mathrm{FU}=$ familiar song with unrelated target.

${ }^{c}$ UR $=$ unfamiliar song with related target.

${ }^{\mathrm{d}} \mathrm{UU}=$ unfamiliar song with unrelated target. 
To sum up, both the RT and error rate results indicated that concreteness played a crucial role in determining the observed behavioral patterns, demonstrating that the subjects were paying attention when performing the word concreteness judgment task.

\subsection{ERP data}

The ERP data were time-locked (1) to the onset of the song primes to examine if the manipulation of song familiarity was valid and (2) to the onset of the targets to examine the meaning processing in lyrics perception. Fig. 2A shows the grand average brainwaves with the comparison of the familiar and unfamiliar song primes in the time window of $0-2 \mathrm{~s}$, and Fig. $2 \mathrm{~B}$ presents the topographic map illustrating the difference between these two conditions. As can be seen from Fig. 2A and B, familiar song primes induce stronger negativity than the unfamiliar ones in the time window of $1-2 \mathrm{~s}$, and the pattern seems to be more prominent on the right anterior sites. Fig. 3A illustrates the averaged waveforms of the related and unrelated targets. As shown in Fig. 3A, the brainwaves in both conditions contain clear N1 and P2 components, especially over the anterior and central electrode sites, followed by a widespread negative-going wave (N400) starting from around $250 \mathrm{~ms}$ and peaking at around 350-400 ms, with larger amplitude elicited by the unrelated than related target condition. By visual inspection, the effect is larger over the midline electrodes. The topographic map of the differences between the related and the unrelated target conditions is depicted in Fig. 3B. To characterize the observed patterns, further statistical tests were conducted.

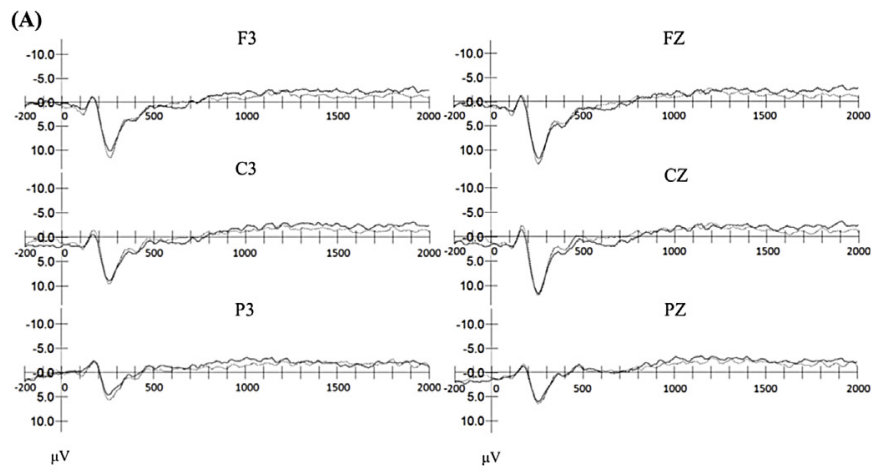

(B)
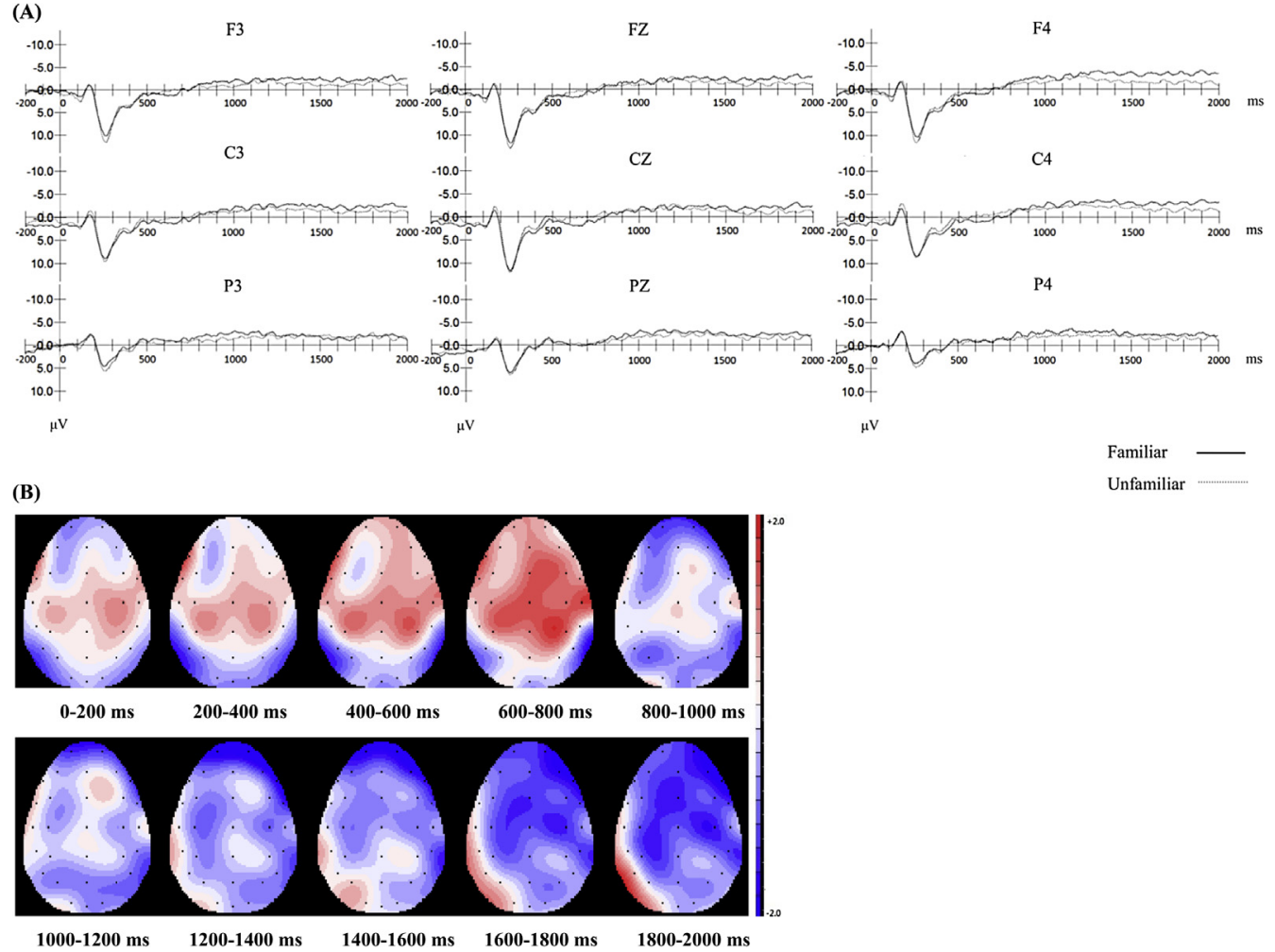

Fig. 2. Familiarity effect on song primes. (A) Grand average ERP waveforms at 9 representative channels in the time window of $0-2 \mathrm{~s}$. The negativity in the right frontal region (F4) is larger in the familiar song condition than in the unfamiliar one. (B) Topographic map for the differences between familiar and unfamiliar songs (familiar - unfamiliar) in the time window of $0-2 \mathrm{~s}$ after the onset of the song primes. (interval: $200 \mathrm{~ms}$; this 2D map is shown with the average on interval). 
(A)
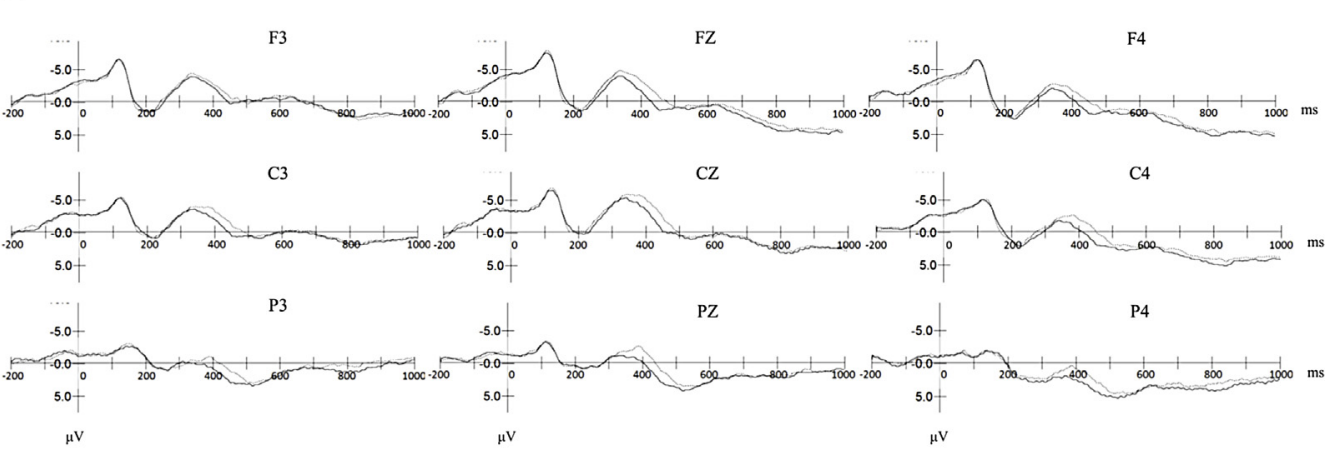

(B)

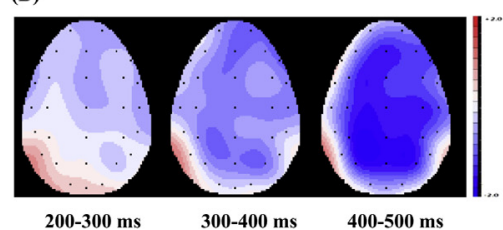

Related

Unrelated

200-300 ms

300-400 ms 400-500 ms

Fig. 3. Relatedness effect on visual targets. (A) Grand average ERP waveforms at 9 representative channels. The N400 for unrelated targets is larger than that for related ones. (B) Topographic map for the differences between related and unrelated target words (unrelated - related) in the time window of $200-500 \mathrm{~ms}$ after the onset of the target words. (interval: $100 \mathrm{~ms}$; this 2D map is shown with the average on interval).

To test whether the manipulation of song familiarity induced different brain response to the song primes, two omnibus repeated measures ANOVAs were carried out separately on the mean amplitudes of the midline channels (FZ, CZ, PZ) and on the lateral regions (LF, RF, LP, RP) at 0-1 and 1-2 s after the onset of song primes. As for the midline analysis, two $2 \times 3$ ANOVAs with the factors of familiarity (familiar, unfamiliar) and electrode (FZ, CZ, PZ) was conducted and no main effects or interactions involving familiarity were found in both time windows $(0-1 \mathrm{~s}$ : familiarity: $\mathrm{F}(1,18)=.305, \mathrm{p}=.587$; electrode: $\mathrm{F}(2,36)=21.366, \mathrm{p}<.001$; familiarity $\times$ electrode: $\mathrm{F}(2,36)=2.083, \mathrm{p}=.139 ; 1-2 \mathrm{~s}$ : familiarity: $\mathrm{F}(1,18)=3.303, \mathrm{p}=.086$; electrode: $\mathrm{F}(2,36)=2.260, \mathrm{p}=.135$; familiarity $\times$ electrode: $\mathrm{F}(2,36)=.572, \mathrm{p}=.570)$. As for the lateral analysis, two $2 \times 4$ ANOVAs with the factors of familiarity (familiar, unfamiliar) and region (LF, RF, LP, RP) were conducted. The analysis between 0 and $1 \mathrm{~s}$ did not reveal any effect involving familiarity (familiarity: $\mathrm{F}(1,18)=.005, \mathrm{p}=.944$; familiarity $\times$ region: $\mathrm{F}(3,54)=.474, \mathrm{p}=.595)$. In the time window of $1-2 \mathrm{~s}$, there was a marginal main effect of familiarity $(\mathrm{F}(1,18)=3.495, \mathrm{p}=.078)$ and a significant interaction between familiarity and region $(\mathrm{F}(3,54)=3.607$, $\mathrm{p}<.05$ ), but follow-up comparisons did not reveal significant differences between familiar and unfamiliar conditions in the 4 regions. To better capture when and where the familiarity factor exerted its effect in the lateral analysis, we divided the 1-2 s time window into 1000-1500 and 1500-2000 ms. The results showed that the previously observed familiarity and familiarity $\times$ region effects mainly came from the 1500-2000 ms time window (1000-1500 ms: familiarity: $F(1,18)=1.78, \mathrm{p}=.19$; familiarity $\times$ region: $\mathrm{F}(3,54)=.95, \mathrm{p}=.37 ; 1500-2000 \mathrm{~ms}$ : familiarity: $\mathrm{F}(1,18)=4.99, \mathrm{p}<.05$; familiarity $\times$ region: $\mathrm{F}(3,54)=5.18, \mathrm{p}<.05)$. Follow-up comparisons revealed marginally larger negativity in the right anterior region in the familiar song condition than in the unfamiliar one $(\mathrm{t}(18)=2.774, \mathrm{p}=.052)$.

Taken together, the analyses indicated that, at 1.5-2 s after the onset of the song excerpts, subjects started to show a familiarity effect in the right frontal region, suggesting that the manipulation of song familiarity was successful.

To examine the meaning processing of lyrics and to explore whether such processing was influenced by song familiarity, the mean amplitudes of brainwaves triggered by the visual targets in the time window of 
350-500 ms were submitted to two ANOVAs at the midline channels (FZ, CZ, PZ) and at the lateral regions (LF, RF, LP, RP). The midline analysis with the factors of familiarity (familiar, unfamiliar), relatedness (related, unrelated) and electrode $(F Z, C Z, P Z)$ showed a main effect of relatedness $(F(1,18)=13.613$, $\mathrm{p}<.005$ ), with the unrelated targets inducing larger $\mathrm{N} 400$ than the related ones. The $\mathrm{N} 400$ relatedness effect suggested that subjects were processing the meaning of the song prime. There was no familiarity main effect and familiarity $\times$ relatedness interaction (familiarity: $\mathrm{F}(1,18)=.279, \mathrm{p}=.604$; familiarity $\times$ relatedness: $\mathrm{F}(1,18)=1.880, \mathrm{p}=.187$ ), showing that song familiarity did not influence the processing of the target and neither did it modulate the relatedness effect on the target. There was also a main effect of electrode, but no other interactions were found (electrode: $\mathrm{F}(1.301,23.409)=12.124$, $\mathrm{p}<.005$; familiarity $\times$ electrode: $\mathrm{F}(2,36)=.275, \mathrm{p}=.761$; relatedness $\times$ electrode: $\mathrm{F}(2,36)=.471, \mathrm{p}=.628$; familiarity $\times$ relatedness $\times$ electrode: $F(1.447,26.049)=.180, p=.765)$. As for the lateral analysis with the factors of familiarity (familiar, unfamiliar), relatedness (related, unrelated) and region (LF, RF, LP, RP), a main effect of relatedness $(F(1,18)=8.855, \mathrm{p}<.05)$ was also found, with larger $\mathrm{N} 400$ being elicited by the unrelated than related targets. Neither the familiarity effect $(\mathrm{F}(1,18)=.257, \mathrm{p}=.618)$ nor the familiarity $\times$ relatedness interaction $(\mathrm{F}(1,18)=.261, \mathrm{p}=.615)$ reached significance. No other significant effects were found (region: $\mathrm{F}(3,54)=1.363, \mathrm{p}=.264$; familiarity $\times$ region: $\mathrm{F}(3,54)=1.321, \mathrm{p}=.270$; relatedness $\times$ region: $\mathrm{F}(3,54)=.540, \mathrm{p}=.497$; familiarity $\times$ relatedness $\times$ region: $\mathrm{F}(3,54)=1.156, \mathrm{p}=.304)$. In sum, both the midline and lateral analyses showed that subjects processed the meaning of the lyrics, as indicated by the N400 relatedness effect on the targets, and that song familiarity did not modulate the relatedness effect.

To rule out the possibility that the absence of the main effect of familiarity and its interaction with relatedness on the visual targets was due to different song familiarity felt by the ERP subjects and by the pilot subjects (i.e. the songs that were familiar to the pilot subjects might be unfamiliar to the ERP subjects), we selected 10 subjects whose song familiarity rating reached an agreement rate above $87 \%$ with that of the pilot subjects. Similar to previous analyses, two three-way ANOVAs on the midline and lateral channels were conducted. A three-way ANOVA on the midline channels with the factors of familiarity, relatedness and electrode (FZ, CZ, PZ) again revealed a main effect of relatedness $(\mathrm{F}(1,9)=6.459, \mathrm{p}<.05)$, but still failed to show any effect involving familiarity (familiarity: $\mathrm{F}(1,9)=.019, \mathrm{p}=.893$; familiarity $\times$ relatedness: $\mathrm{F}(1,9)=3.224, \mathrm{p}=.106$; familiarity $\times$ electrode: $\mathrm{F}(2,18)=1.678, \mathrm{p}=.215$; familiarity $\times$ relatedness $\times$ electrode: $\mathrm{F}(2,18)=.542, \mathrm{p}=.591)$. Another threeway repeated ANOVA on the lateral regions with the factors of familiarity, relatedness and region (LF, $\mathrm{RF}, \mathrm{LP}, \mathrm{RP})$ revealed the same pattern: there was a main effect of relatedness $(\mathrm{F}(1,9)=5.794, \mathrm{p}<.05)$, but there was no involvement of familiarity (familiarity: $\mathrm{F}(1,9)=.360, \mathrm{p}=.563$; familiarity $\times$ relatedness: $F(1,9)=1.867, p=.205$; familiarity $\times$ region: $F(3,27)=.238, p=.709$; familiarity $\times$ relatedness $\times$ region: $\mathrm{F}(3,27)=.403, \mathrm{p}=.627)$.

In sum, our results clearly showed that the N400 was stronger for the unrelated targets than the related ones in both midline and lateral analyses and that this relatedness effect did not differ by the familiarity factor.

\section{Discussion}

The purpose of the present ERP study was to investigate whether people process the meaning of song lyrics spontaneously, and, if they do, whether such processing would be affected by song familiarity. We adopted a cross-modal semantic priming paradigm, with familiar or unfamiliar auditory song excerpts as the primes and visual words related or unrelated to the final word of the lyrics as the targets, and subjects' task was to judge the concreteness of the targets. The results revealed that the N400 amplitude was smaller in the semantically related than unrelated target words, indicating that it was easier for the subjects to access related than unrelated targets. The easier access was possibly because the semantic features of related targets had already been pre-activated when the subjects processed the final word in the lyrics, suggesting that lyrics processing was automatically engaged even though that was not necessary in completing the required experimental task. As noted in Introduction, earlier literature on song perception usually presented songs sung/synthesized a cappella (Besson et al., 1998; Bonnel et al., 2001; Sammler et al., 2010; Yasui et al., 2009) and directed subjects' attention to the lyrics or melody (Besson et al., 1998; Bonnel et al., 2001; Crowder et al., 1990; Gordon et al., 2010; Hébert \& Peretz, 2001; Poulin-Charronnat et al., 2005; Serafine et al., 1984). To make our 
experiment more ecologically valid, we used pop songs as experimental materials because people usually listen to them in a natural setting (e.g. at home, during commuting). Also, we played these songs in their original version and directed the subjects' attention away from the songs by asking them to judge the concreteness of the visual target, which was unrelated to the meaning of the lyrics. Even with such manipulations, people still processed the meaning of lyrics, showing that semantic processing of lyrics is automatic.

Importantly, the N400 relatedness effect of the targets was not modulated by the familiarity of the song primes, indicating that the semantic processing of lyrics was not reduced by song familiarity. We should point out that the lack of the familiarity involvement was unlikely due to the ERP subjects' different familiarity ratings from those of the pilot subjects' because the results from 10 subjects who had high agreement rate of familiarity also failed to show a familiarity effect. It is also not possible that the lack of the effect could be attributed to the subjects' insensitivity to the familiarity manipulation of the song excerpts since significant familiarity and familiarity $\times$ region effects were found in the brain response to song primes, especially during $1.5-2 \mathrm{~s}$ after the song onset, showing that subjects might have been engaged in retrieving the familiar song per se, or its associated emotion/memories (Janata, 2009; Pereira et al., 2011), no later than 2 s after the song started.

Our results clearly demonstrated that no matter how many times people have listened to a song, they still automatically process the meaning of its lyrics. This might seem counterintuitive. As discussed in Introduction, familiarity of music is mainly achieved through repetition (Peretz et al., 1998; Thompson \& Russo, 2004). However, while repetition in music retains communicative significance, repetition of a word should induce semantic satiation (Margulis, 2013; Severance \& Washburn, 1907). If lyrics are like regular spoken sentences, we should find more reduced, if not null, relatedness effect in familiar songs than in unfamiliar ones because familiar lyrics have been repeated multiple times so they should undergo shallow or no semantic processing when encountered. But that was not what we found. We found that familiar lyrics were still processed as thoroughly as unfamiliar ones, as reflected in the similar amplitudes of the relatedness effect of the targets following both types of songs. The immunity to semantic satiation caused by repetition suggests that lyrics may actually be different from regular speech, at least in a higher communicative level. That is, once linguistic elements are embedded with melody to form a song, they are part of the song and retain their communicative significance (e.g. expressing happiness or sadness of love) even after being repeated many times. This finding of the top down effect of higher-level status change of linguistic material (e.g. from speech to songs in our study) on lower-level semantic processing may add an interesting perspective into future research on language modularity and on the independent/interactive views of lyrics processing.

We should clarify that we are not arguing against the idea that lyrics and speech are similar, as we have discussed in Introduction that many neurophysiological and neuroimaging studies have discovered that similar brain regions support song and speech processing (Gordon et al., 2010; Koelsch et al., 2000, 2002; Maess et al., 2001; Merrill et al., 2012; Patel et al., 1998). Instead, we argue that, although sharing many similarities, lyrics and speech processing may still differ at a higher communicative level, which affects whether/how they are processed after being repeated many times.

In sum, our study clearly indicated that people processed the meaning of lyrics in natural song perception and that such semantic processing did not differ in listening to familiar or unfamiliar songs.

\section{Conclusions}

The current study extends our understanding of song perception. We found that people automatically process the meaning of song lyrics and that such processing would not be reduced by song familiarity. We argue that song lyrics and speech processing are different at a higher communicative level, which may affect whether/how they are processed after being repeated multiple times.

\section{Acknowledgments}

This research was partially supported by the "Aim for the Top University Project" and "Center of Learning Technology for Chinese" of National Taiwan Normal University (NTNU), sponsored by the Ministry of Education, Taiwan, R.O.C. (http://www.edu.tw/) and the "International Research-Intensive 
Center of Excellence Program" of NTNU and Ministry of Science and Technology, Taiwan, R.O.C. under Grant no. MOST 104-2911-I-003-301. We would like to thank the two anonymous reviewers for their helpful, constructive suggestions and comments on an earlier version of the manuscript.

\section{References}

Besson, M., Faïta, F., Peretz, I., Bonnel, A.-M., \& Requin, J. (1998). Singing in the brain: independence of lyrics and tunes. Psychological Science, 9, 494-498.

Bigand, E., Tillmann, B., Poulin, B., D'Adamo, D. A., \& Madurell, F. (2001). The effect of harmonic context on phoneme monitoring in vocal music. Cognition, 81(1), B11-B20.

Bonnel, A.-M., Faita, F., Peretz, I., \& Besson, M. (2001). Divided attention between lyrics and tunes of operatic songs: evidence for independent processing. Attention, Perception, \& Psychophysics, 63(7), 1201-1213. http://dx.doi.org/10.3758/bf03194534.

Crowder, R., Serafine, M., \& Repp, B. (1990). Physical interaction and association by contiguity in memory for the words and melodies of songs. Memory \& Cognition, 18(5), 469-476. http://dx.doi.org/10.3758/bf03198480.

Gordon, R. L., Schön, D., Magne, C., Astésano, C., \& Besson, M. (2010). Words and melody are intertwined in perception of Sung Words: EEG and behavioral evidence. PLoS ONE, 5(3), e9889. http://dx.doi.org/10.1371/journal.pone.0009889.

Greenhouse, S., \& Geisser, S. (1959). On methods in the analysis of profile data. Psychometrika, 24(2), 95-112. http://dx.doi.org/ $10.1007 / \mathrm{bf02289823.}$

Hébert, S., \& Peretz, I. (2001). Are text and tune of familiar songs separable by brain damage? Brain and Cognition, 46(1), $169-175$.

Hébert, S., Racette, A., Gagnon, L., \& Peretz, I. (2003). Revisiting the dissociation between singing and speaking in expressive aphasia. Brain, 126(8), 1838-1850.

Janata, P. (2009). The neural architecture of music-evoked autobiographical memories. Cerebral Cortex. bhp.008.

Koelsch, S., Gunter, T., Friederici, A., \& Schröger, E. (2000). Brain indices of music processing:"nonmusicians" are musical. Journal of Cognitive Neuroscience, 12(3), 520-541.

Koelsch, S., Gunter, T. C., Zysset, S., Lohmann, G., \& Friederici, A. D. (2002). Bach speaks: a cortical "language-network" serves the processing of music. NeuroImage, 17(2), 956-966.

Kutas, M., \& Federmeier, K. D. (2011). Thirty years and counting: finding meaning in the N400 component of the event-related brain potential (ERP). Annual Review of Psychology, 62(1), 621-647. http://dx.doi.org/10.1146/annurev.psych.093008.131123.

Kutas, M., \& Hillyard, S. A. (1980). Reading senseless sentences: brain potentials reflect semantic incongruity. Science, 207, 203-205.

Kutas, M., \& Hillyard, S. A. (1984). Brain potentials during reading reflect word expectancy and semantic association. Nature, 307, $161-163$.

Maess, B., Koelsch, S., Gunter, T. C., \& Friederici, A. D. (2001). Musical syntax is processed in Broca's area: an MEG study. Nature Neuroscience, 4(5), 540-545.

Margulis, E. H. (2013). Repetition and emotive communication in music versus speech. Frontiers in Psychology, 4.

Merrill, J., Sammler, D., Bangert, M., Goldhahn, D., Lohmann, G., Turner, R., et al. (2012). Perception of words and pitch patterns in song and speech. Frontiers in psychology, 3.

Morrongiello, B. A., \& Roes, C. L. (1990). Children's memory for new songs: Integration or independent storage of words and tunes? Journal of Experimental Child Psychology, 50(1), 25-38.

Oldfield, R. C. (1971). The assessment and analysis of handedness: the Edinburgh inventory. Neuropsychologia, 9(1), 97-113. http://dx.doi.org/10.1016/0028-3932(71)90067-4.

Patel, A., Gibson, E., Ratner, J., Besson, M., \& Holcomb, P. (1998). Processing syntactic relations in language and music: an eventrelated potential study. Journal of Cognitive Neuroscience, 10(6), 717-733.

Pereira, C. S., Teixeira, J., Figueiredo, P., Xavier, J., Castro, S. L., \& Brattico, E. (2011). Music and emotions in the brain: familiarity matters. PLOS ONE, 6(11), e27241.

Peretz, I. (1996). Can we lose memory for music? A case of music agnosia in a nonmusician. Journal of Cognitive Neuroscience, 8(6), 481-496.

Peretz, I., Gaudreau, D., \& Bonnel, A.-M. (1998). Exposure effects on music preference and recognition. Memory \& Cognition, 26(5), 884-902.

Poulin-Charronnat, B., Bigand, E., Madurell, F., \& Peereman, R. (2005). Musical structure modulates semantic priming in vocal music. Cognition, 94(3), B67-B78.

Racette, A., Bard, C., \& Peretz, I. (2006). Making non-fluent aphasics speak: sing along! Brain, 129(10), 2571-2584.

Sammler, D., Baird, A., Valabrègue, R., Clément, S., Dupont, S., Belin, P., et al. (2010). The relationship of lyrics and tunes in the processing of unfamiliar songs: a functional magnetic resonance adaptation study. The Journal of Neuroscience, 30(10), $3572-3578$.

Samson, S., \& Zatorre, R. J. (1991). Recognition memory for text and melody of songs after unilateral temporal lobe lesion: evidence for dual encoding. Journal of Experimental Psychology: Learning, Memory, and Cognition, 17(4), 793.

Serafine, M. L., Crowder, R. G., \& Repp, B. H. (1984). Integration of melody and text in memory for songs. Cognition, 16(3), 285-303.

Serafine, M. L., Davidson, J., Crowder, R. G., \& Repp, B. H. (1986). On the nature of melody-text integration in memory for songs. Journal of Memory and Language, 25(2), 123-135.

Severance, E., \& Washburn, M. F. (1907). The loss of associative power in words after long fixation. The American Journal of Psychology, 182-186.

Thompson, W. F., \& Russo, F. A. (2004). The attribution of emotion and meaning to song lyrics. Paper presented at the Polskie Forum Psychologiczne.

Yasui, T., Kaga, K., \& Sakai, K. L. (2009). Language and music: differential hemispheric dominance in detecting unexpected errors in the lyrics and melody of memorized songs. Human Brain Mapping, 30(2), 588-601. 